\title{
EDUCAÇÃO AMBIENTAL, QUALIDADE DE VIDA E SUSTENTABILIDADE
}

\author{
Maria Cecilia Focesi Pelicioni*
}

RESUMO: O presente artigo procura mostrar que uma nova visão de mundo está ganhando cada vez mais espaço entre as pesscas por meio da Educaçăo Ambiental, a qual objetiva a melhoria da qualidade de vida no planeta. A Educaçăo Ambiental busca a valorizaçăo da vida, a formaçăo de um novo estilo de vida, sem consumismo excessivo, sem o desperdício de recursos e sem degradaçăo ambiental. Apresenta também a opiniăo de alguns autores a respeito do "desenvolvimento sustentável" como uma forma de crescimento econômico aliada à justiça social eà satisfaçăo das necessidades dos excluídos.

PALAVRAS-CHAVE: educação ambiental, qualidade de vida e sustentabilidade.

* Profa. Dra. do Departamento de Prática de Saúde Pública da Faculdade de Saúde Pública da USP e Diretora de Políticas Públicas da Secretaria Municipal do Verde e do Meio Ambiente da PMSP. Av. Dr. Amaldo, 715 - térreo - São Paulo - SP CEP 01246-904 


\section{EDUCAÇÃO AMBIENTAL}

De acordo com a Primeira Conferência Intergovernamental sobre Educação Ambiental, realizada em 1977 em Tbilisi, Georgia (ex URSS) a educação ambiental é considerada um processo permanente, no qual os individuos e a comunidade tomam consciência do meio ambiente e adquirem os conhecimentos, os valores, as habilidades, as experiências e a determinação que os tomam aptos a agir individual e coletivamente para resolver problemas ambientais presentes e futuros (DIAS, 1992, p. 92).

Foi definida como uma dimensão dada ao conteúdo e à prática da educação, orientada para a resolução dos problemas concretos do meio ambiente através de enfoques interdisciplinares e de uma participação ativa e responsável de cada indivíduo e da coletividade. Essa definição é adotada no Brasil e pela maioria dos países membros da Organização das Nações Unidas-ONU (DIAS, 1994, p. IX).

A Educação Ambiental, de acordo com DIAS (1994), se caracteriza por incorporar as dimensões sociais, políticas, econômicas, culturais, ecológicas e éticas, o que significa que ao tratar de qualquer problema ambiental, deve-se considerar todas as dimensöes. E continua o autor ..."a maior parte dos problemas ambientais tem suas raizes na miséria, que por sua vez é gerada por políticas e problemas econômicos concentradores de riqueza e responsáveis pelo desemprego e degradação ambiental".

Entre as orientações de Tbilisi destaca-se ainda que a Educação Ambiental deve considerar o meio ambiente em sua totalidade, em seus aspectos naturais e criados pelo homem. Enquanto processo contínuo e permanente a Educação Ambiental, deve atingir todas as fases do ensino formal e não formal; deve examinar as questões ambientais do ponto de vista local, regional, nacional e internacional, analisando suas causas, consequências e complexidade. Deve também, desenvolver o senso crítico e as habilidades humanas necessárias para resolver tais problemas e utilizar métodos e estratégias adequadas para aquisição de conhecimentos e comunicação, valorizando as experiências pessoais e enfatizando atividades práticas delas decorrentes (DIAS, 1994).

Das recomendações do Seminário Latino-americano realizado em Buenos Aires, Argentina em 1988, algumas completam as orientações acima descritas: a Educação Ambiental deve fazer parte da política ambiental dos paises; adaptar-se às característi- 
cas culturais especificas das populações envolvidas no processo educativo; deve considerar o contexto de subdesenvolvimento dos países da América do Sul e se transformar num instrumento idôneo para a integração e 0 apoio mútuo entre as nações da região. Deve também salientar a necessidade de criação de um novo estilo de desenvolvimento que inclua crescimento econômico, igualdade social e conservação de recursos naturais, capaz de propiciar relações mais humanas, fraternas e justas entre os homens, e destes com o seu entorno natural, atingindo niveis crescentes de qualidade de vida (DIAS, 1994, XIV).

Já durante a Conferência das Nações Unidas sobre o Meio AMbiente e o Desenvolvimento realizado no Rio de Janeiro em 1992 recomendou-se que a educação ambiental deveria: reorientar a educação para o desenvolvimento sustentável de forma a compatibilizar objetivos sociais de acesso às necessidades básicas; com objetivos ambientais de presenvação da vitalidade e diversidade do planeta garantindo como direito aos cidadãos um ambiente ecologicamente saudável e com objetivos econômicos; aumentar a conscientização popular, considerar 0 analfabetismo ambiental e promover treinamento.

As organizações não governamentais reunidas no Fórum Global da Rio-92 formularam o trabalho de Educação Ambiental para Sociedades Sustentáveis e Responsabilidade Global que estabeleceram alguns princípios, dos quais pode-se citar:

- a educação ambiental é um direito de todos, somos todos aprendizes e educadores;

- deve ter como base o pensamento crítico e inovador em qualquer tempo ou lugar em seus modos formal, não formal e informal promovendo a transformação e a construção da sociedade.

- é individual e coletiva. Tem o propósito de formar cidadãos com consciência local e planetária que respeitem a autodeterminação dos povos e a soberania das nações;

- a educação ambiental não é neutra, mas ideológica;

- deve integrar conhecimentos, aptidões, valores, atitudes e ações, convertendo cada oportunidade em experiências educativas de sociedades sustentáveis. 
A educação ambiental tem como objetivo, portanto, formar a consciência dos cidadãos e transformar-se em filosofia de vida de modo à levar a adoção de comportamentos ambientalmente adequados, investindo nos revursos e processos ecológicos do meio ambiente. A educação ambiental, deve necessariamente transformar-se em ação.

Enquanto prática político-pedagógica, a Educação Ambiental determinada histórica e socialmente, pretende possibilitar o desenvolvimento e a escolha de estratégias de ação, que venham contribuir para a construção do processo de cidadania e para a melhoria da qualidade de vida da população.

\section{QUALIDADE DE VIDA}

A Organização Mundial da Saúde-OMS (1996) define Qualidade de Vida como as percepções individuais sobre sua posição de vida no contexto dos sistemas de cultura e de valores em que vivem, e em relação às suas metas, expectativas, padrões e preocupações. É um conceito abrangente, que incorpora de uma forma complexa, a saúde física, o estado psicológico, o nível de dependência, as relações sociais, as crenças pessoais e o relacionamento com caracteríticas que se destacam no ambiente.

Esta definição mostra as visões que referem a qualidade de vida como uma avaliação subjetiva que induz dimensões positivas e negativas e que se apoia no contexto cultural, social e ambiental. A OMS define seis domínios mais amplos que descrevem os aspectos centrais da qualidade de vida que atravessam as culturas: um domínio físico (energia, fadiga), um domínio psicológico (sentimentos positivos), o nivel de independência (mobilidade), as relações sociais (apoio social prático), o ambiente (acessibilidade à atenção à saúde) e as crenças pessoais/espiritualidade (sentido da vida). Os domínios da saúde e da qualidade de vida são complementares e se sobrepõem.

A qualidade de vida reflete a percepção dos indivíduos de que suas necessidades estão sendo satisfeitas e que eles não têm negadas oportunidades para atingir a felicidade e a plenitude, com relação ao status físico de saúde, ou as condições sociais ou econômicas. A meta de se melhorar a qualidade de vida, ao lado da prevenção de problemas de saúde evitáveis, tem uma importância cada vez maior na promoção da saúde. Isso é particularmente importante para o atendimento das pessoas idosas, das pessoas com doenças crônicas, dos doentes terminais e dos deficientes (OMS, 1998, p. 
31). Qualidade de vida é a expressão que define o grau de satisfação atingido pelos indivíduos ou população, no que diz respeito às suas necessidades consideradas fundamentais. É a somatória de fatores decorrentes da interação entre sociedade e ambiente, atingindo a vida no que concerne às suas necessidades biológicas, psíquicas e sociais inerentes e/ou adquiridas (COIMBRA, 1985).

Se expressa mediante a utilização de indicadores sociais concretos e objetivos como a taxa de desemprego, a densidade populacional e outros subjetivos, abstratos, baseados em informações colhidas diretamente dos indivíduos que compõem uma população em estudo. Não há como dissociar qualidade de vida do comportamento do indivíduo e da sociedade, resultante da sua organização e do seu desenvolvimento cultural (PELICIONI, 1995, p. 40).

Cultura aqui, entendida como o resultante do crescimento praticamente infinito do conhecimento humano.

Para FORATTINI (1991), qualidade de vida, em sua essência, se traduz então, pela satisfação em viver. De acordo com esse autor, "o estado de satisfação ou insatisfação constitue na verdade, experiência de caráter pessoal e está ligado ao propósito de obtenção de melhores condições de vida. $O$ grau de ajustamento às situaçōes existentes, ou então, o desejo de mudança, poderão servir para avaliar a presença ou ausência de satisfação".

Para HÖRNQUIST (1990) é o grau de satisfação de necessidades nas áreas física, psicológica e social. Essas necessidades podem ser concretas e dizem respeito a áreas mais genéricas como alimentação e moradia, enquanto que as outras, são de natureza mais particular como a auto-estima e a auto-realização.

Podemos considerar como determinantes da qualidade de vida:

1. os determinantes orgânicos ou biológicos que dizem respeito à saúde e à doença;

2. os psicológicos tais como obem-estar e a percepção, a identidade, a autoestima, o estado emocional $\mathrm{e}$ a afetividade, $\mathrm{o}$ aprendizado e a criatividade, o conhecimento e a habilidade;

3. os determinantes sociais: o relacionamento em geral, a vida familiar, a vida sexual, a privacidade; 
4. os determinantes comportamentais: a autodeterminação e a mobilidade, a vida profissional, hábitos como fumo, álcool, a alimentação, o repouso, o lazer entre outros;

5. os materiais: a economia privada e a auto-sustentação, a habitação, os bens e a renda;

6. os estruturais: o significado da própria vida, a posição social e a concepção sócio-política, entre outras (HÖRNQUIST, 1990).

A qualidade de vida coletiva pode ser considerada como a resultante de condições sócio-ambientais e estruturais que se desenvolvem na sociedade.

Entre os indicadores sociais usados para avaliá-los podemos citar:

1. os indicadores ambientais que dizem respeito à qualidade da água, ar e solo, à poluição e contaminação;

2. os indicadores habitacionais: a densidade, a disponibilidade e as condições de habitabilidade;

3. os urbanos: a concentração populacional a comunicação e 0 transporte, a educação, a segurança, a poluição sonora e visual, local e paisagística;

4. os sanitários: a morbidade e a mortalidade, a assistência médica e hospitalar, o estado nutricional;

5. os sociais: as condições sócio-econômicas e classes, o consumo, as necessidades e desigualdades, a família e a sexualidade, as condições de trabalho e profissão, a recreação, o lazer e o turismo, como também, o sistema político-administrativo (FORATTINI, 1991).

Todos esses indicadores se inter-relacionam intimamente, devem ser considerados em conjunto e têm caráter essencialmente social.

O conceito de qualidade de vida, portanto, transcede o conceito de padrão ou nivel de vida, de satisfação das necessidades humanas do TER para a valorização da existência humana do SER e deve ser avaliada pela capacidade que tem determinada sociedade de proporcionar oportunidades de realização pessoal a seus individuos no sentido psíquico, social e espiritual ao mesmo tempo em que Ihes garante um nivel de vida minimamente aceitável. 
Uma nova visão do mundo está aos poucos se estruturando com uma proposta de estilo de vida, caracterizada pela recusa ao materialismo e consumismo exaberbados e por um progressivo deslocaamento de Ter para o Ser. Uma moderna cultura urbana que privilegia a troca de experiências individuais e a atmosfera espiritual vivenciada por novos valores, novos significados e laços com o ambiente da vida cotidiana.

Este novo estilo de vida pós-consumismo, necessário pois os recursos do planeta são finitos, deslocará a atenção das coisas para as pessoas, do ter para a arte de viver.

Esta revalorização da vida permitirá um aumento da capacidade de escolha e a busca da satisfação dos sonhos e desejos na arte e na filosofia, na religiāo e na ciência, objetivando a auto-realização. Só então, se conseguirá viver a vida com "qualidade".

\section{DESENVOLVMENTOSUSTENTÁVEL}

O conceito de desenvolvimento sustentado tem sido bastante discutido e utilizado com enfoques muito diferentes, inclusive, com o intuito de ratificar posiçőes, político ideológicas que defendem os interesses capitalistas e de manutenção da situação sócio-econômica cultural atual, com todas as desigualdades e com o injusto processo de exclusão crescente que a caracteriza. Utilizado nos discursos governamentais e empresariais, muitas vezes ligado ao conceito de progresso, o termo desenvolvimento pode se traduzir no caminhar das sociedades, para niveis cada vez mais elevados de crescimento ilimitado e de obtenção de riquezas materiais, entretanto pode significar ainda etapas históricas sucessivas de passagem de uma sociedade tradicional para uma sociedade moderna e finalmente, para a de consumo de massa ou pode também ser visto como um processo de mudanças sócio-políticas estruturais, principalmente por autores da América Latina (DIEGUES, 1992, p. 23).

Uma revisão dos conceitos desenvolvimentistas realizada nos anos 70 , a partir de uma reflexão sobre a dominação ideológica, econômica e política baseada na economia de mercado sobre as demais formas de organização social não capitalistas levou à proposição de um estilo de desenvolvimento que não acreditava mais em um crescimento econômico exponencial ilimitado, era contra a exportação maciça de recursos naturais locais; contra a degradação ambiental e o consumismo e contra a fé 
indiscriminada no progresso obtido pela ciência e a tecnologia; ao contrário, propunha que a qualidade de vida fosse o objetivo fundamental de qualquer desenvolvimento (DIEGUES, 1992, p. 25) com a satisfação das necessidades básicas da população alcançadas por meio da utilização de tecnologias social e ecologicamente adequadas.

Essa nova ética desenvolvimentista propunha também uma descentralização nas tomadas de decisão e a solidariedade para as gerações futuras, o que aparece claramente no relatório da Comissão Mundial para o Meio Ambiente e Desenvolvimento conhecida como Comissão Brundtland (NOSSO FUTURO COMUM, 1987) que define o desenvolvimento sustentável em sua nova ordem econômica internacional, é aquele que atende às necessidades do presente sem comprometer a capacidade das geraçōes futuras também atenderem às suas. É um processo de mudança no qual a exploração dos recursos, orientação dos investimentos, os rumos do desenvolvimento tecnomógico e a mudança institucional estão de acôrdo com as necessidades atuais e futuras; é uma correção, uma retomada do crescimento alterando a qualidade do desenvolvimento. A avaliação global dessa Comissão é que a economia internacional deve acelerar o crescimento mundial, respeitando, porém, as limitações ecológicas. De acordo com HERCULANO (1992) "os ambientalistas têm se queixado de que a noção do desenvolvimento sustentável, que é deles, vem sendo perversamente invertida e reinterpretada de modo dúbio e vago como uma estratégia de expansão do mercado e do lucro", quando, na verdade, de subentender um conjunto de mudanças chaves na estrutura de produção e consumo, invertendo o quadro de degradação ambiental e de miséria social a partir de suas causas.

Para BARONI (1992) que realizou estudo sobre vários autores e o significado por eles atribuído, o termo desenvolvimento sustentável tem sido utilizado por interesses diversos como símbolo de um consenso - ideal que está longe de ser construído -, já que a idéia tem ficado no plano dos discursos, onde as ambigüidades são muitas e não se procura explicitar a realidade atual dos conflitos sociais e econômicos pelo uso dos recursos naturais. Os diferentes atores sociais e os diferentes países não têm os mesmos interesses nem a mesma idéia do que seja desenvolvimento sustentável. Hoje, há realmente, um consenso social, mas, sobre o que vem se tornando insustentável.

ESPINOSA (1993) considera, entretanto, que os esforços para operacionalizar o desenvolvimento sustentável na escla planetária, são dificultados não apenas pela complexidade do tema, mas, também, pelos interesses estratégicos e econômicos ligados ao assunto. Segundo o autor, para que o caminho do desenvolvimento sustentável 
seja trilhado na prática é necessário desenvolver sistemas de gestão, que permitam a tomada de decisões apesar de todos os problemas e incertezas apontados.

De acordo com MINAYO (1998) o conceito de desenvolvimento sustentável “deixou de ser a palavra mágica que durante quase meio século (a partir da $2^{a}$ Guerra Mundial) embalou os planos dos países desenvolvidos e os sonhos dos subdesenvolvidos, numa visão evolucionista do progresso, numa corrida de domínio sem limites da natureza e das matérias primas, de forma desenfreada, predatória e anárquica. Hoje a palavra desenvolvimento parece inspirar mais problemas que soluções, num mundo que conseguiu globalizar fomes, continentais, conflitos étnicos, comprometimento de qualidade de vida, poluição, desemprego crescente e estrutural, violência, drogas, esgotamento de recursos naturais, ameaças a extinção de espécies e desastres ecológicos (p.4).

Segundo DIEGUES (1992), não existe um único paradigma de sociedade do bem estar (a ocidental) a ser atingida por meio do desenvolvimento e do progresso linear, mas, vários tipos de sociedades sustentáveis, “ancoradas em modos particulares, históricos e culturais de relações com os vários ecosistemas existentes na bioesfera e dos seres humanos entre $\mathrm{si}^{\text {" }}$ (p. 22). Isso implica no reconhecimento da existência de uma grande diversidade ecológica, biológica e cultural entre os povos.

A conceituação de sociedades sustentáveis, está se formando e exige a elaboração de novos paradigmas, se baseia na necessidade de se manter a diversidade ecológica, social e cultural dos povos, das culturas e modos de vida com opções econômicas e tecnológicas diferenciadas voltadas principalmente para o desenvolvimento harmonioso das pessoas e de suas relações com o conjunto do mundo natural (DIEGUES, 1992, pg 29).

Para REIGOTA (1995), "O meio ambiente latino-americano exige que a educação ambiental enfrente o desafio da mudança de mentalidade sobre as idéias de modelo de desnevolvimento baseado na acumulação econômica, no autoritarismo político, no saque aos recursos naturais, no desprezo, às culturas de grupos minoritários e aos direitos fundamentais do homem". Essa "educação política deve estar empenhada na formação do cidadão nacional, continental e planetário baseando-se no diálogo de culturas e de conhecimento entre povos, gerações e gêneros".

E como diz IANNI (1993) é preciso formar o homem como cidadão do mundo. 
Para BROOKS, citado por HERCULANO (1992, p. 34), o desenvolvimento sustentável "pode ter um sentido profundamente radical, de igualdade e justiça social, de preservação, de diversidade cultural, de auto-determinação e de integridade ecológica, mas, pode também ser uma noção conservadora e entendida dentro de um marco tradicional de teoria econômica", sinônimo de crescimento sustentável, que leva, portanto, à desigualdade.

O movimento ambientalista surgiu como um manifesto pela sobrevivência do planeta, de bichos e plantas ameaçados pela extinçäo e no Terceiro Mundo, assumiu a forma de defesa da sobrevivência social dos desvalidos, abraçando a questão ética. Os ecologistas sociais, por outro lado, querem mais que a sobrevivência, querem a felicidade posta como questão política e coletiva.

Sob o aspecto ético, não se aceita mais que o desenvolvimento exponha o patrimônio natural a formas de exploraçăo que aumentem as diferenças sócio-econômicas, esgotem os recursos naturais e poluam os espaços naturais e construídos, sem pensar nas gerações futuras, mas, ao contrário exige-se uma sociedade sustentável que atenda às necessidades sociais de toda a população inclusive a dos excluidos com igualdade e justiça.

\section{CONCLUSÃO}

"Os modelos econômicos adotados no Brasil ao longo da história têm provocado fortes concentrações de renda e riqueza com exclusão de expressivos segmentos sociais resultando, em grande parte, nos problemas que o país enfrenta. Ao mesmo tempo em que degradam o homem, sua qualidade de vida e seu estado de saúde, esses padrões de desenvolvimento vêm favorecendo a degradação ambiental por meio da exploração predatória de recursos naturais e poluição, às quais por sua vez, têm gerado impactos nas condições de saúde e qualidade de vida da população" (MINISTÉRIO DA SAÚDE, 1995).

A situação de ambiente e saúde do país resulta direta e indiretamente das políticas públicas, econômicas e sociais e não pode ser considerada independentemente dessas políticas. 
Esas políticas públics precisam basear seus planejamentos no diagnóstico da realidade local, nas necessidades e interesses da população, nos recursos disponiveis e na legislação vigente e devem estar associadas à educação em saúde ambiental, que sozinha poderá resolver muito pouco.

A última Constituição, estabelece a saúde "como direito de todos e dever do Estado, garantida mediante o estabelecimento de políticas sociais e econômicas, que visem à redução do risco de doença e de outros agravos e ao acesso universal e igualitário às ações e serviços para sua promoção, proteção e recuperação" (art. 196). Determina também, que "todos têm direito ao meio ambiente ecologicamente equilibrado, bem de uso comum do povo e essencial à sadia qualidade de vida, impondo-se ao Poder Público e à coletividade, o dever de defendê-lo e preservá-lo, para as presentes e futuras gerações (art. 225) e que cabe ao poder público promover a Educação Ambiental em todos os niveis de ensino e a conscientização pública para a preservação do Meio AMbiente (art. 225-VI).

A legislação, embora preconize a promoção da saúde de forma integrada com a proteção do meio ambiente, necessita ainda de regulamentação e um controle e gestão ambientais eficazes de modo a garantir realmente aos cidadãos o direito à saúde e a um ambiente equilibrado e saudável no contexto do desenvolvimento sustentável. Os Códigos Ambientais dos estados e dos municipios têm um papel muito importante na implementação das leis assim como os Conselhos Estaduais e Municipais de Saúde e Meio Ambiente que com a participação popular exercerão o controle social necessário para que as leis sejam cumpridas.

Para que isso ocorra, é preciso formar recursos humanos conscientes, críticos e éticos, aptos portanto, a enfrentar esse novo paradigma. A educação ambiental em todos os niveis tem procurado desempenhar esse difícil papel resgatando valores como o respeito à vida e à natureza, entre outros de forma a tornar a sociedade humana mais justa e feliz.

À Educação Ambiental, portanto, cabe contribuir para o processo de transformação da sociedade atual em uma sociedade sustentável, centrado no exercício responsável da cidadania, que considere a natureza como um bem comum, leve em conta a capacidade de regeneração dos recursos materiais, promova a distribuição eqüitativa da riqueza gerada e favoreça condições dignas de vida para as gerações atuais e futuras (SADER, 1992). 


\section{REFEREÊNCIAS BIBLIOGRÁFICAS}

BARONI, M. Ambigüidade e deficiências do conceito de desenvolvimento sustentável. Rev. Adm.Empr. 32(2):14-24, 1992.

BRASIL. Constituiçăo da República Federativa do Brasil. São Paulo, IMESP, 1988. Cap. II Art. 196 e Cap. IV art. 225, 1988.

CARVALHO, I. Ecologia, desenvolvimento e sociedade civil. In: Rev. Adm. Publica, 25(4):245, 1991

COIMBRA, J. de A.A. O outro lado do meio ambiente. São Paulo, CETESB/ASCETESB, 1985.

COMISSÃO MUNDIAL PARA MEIO AMBIENTE E DESENVOLVIMENTO. Nosso futuro comum. Rio de Janeiro, Fundação Getúlio Vargas, 1988.

DIAS, G.F. Educação ambiental: princípios e práticas. São Paulo, Gaia, 1992.

DIEGUES, A.C.S. Desenvolvimento sustentável ou sociedades sustentáveis - da crítica dos modelos aos novos paradigmas. S. Paulo em Perspec. 6(1/2): 22-9, 1992.

ESPINOSA, H.R.M. Desenvolvimento e meio ambiente sob nova ótica. Ambiente, 7(1):40-4, 1993.

FORATTINI, O.P. Qualidade de vida e meio urbano: a cidade de São Paulo, Brasil. Rev. Saúde Pública, 25:75-86, 1991.

HERCULANO, S.C. Do desenvolvimento (in)sustentável à sociedade feliz. In: VIOLA, E. et al. Ecologia ciência e política: participação social, interesses em jogo e luta de idéias no movimento ecológico. Rio de Janeiro, Devan, 1992. p. 9-45.

HORNQÜIST, J.O. Quality of life: concept and assessment. Scand. J. Soc. Med., 18:69$79,1990$.

IANNI, O. A sociedade global. $2^{2}$.ed. Rio de janeiro, Civilização Brasileira, 1993.

MINAYO, M.C. de S. Saúde e ambiente no processo de desenvolvimento. Ciênc. Saúde Coletiva, 3(2):4-5, 1998.

MINISTÉRIO DA SAÚDE. Plano nacional de saúde e ambiente no desenvolvimento sustentável diretrizes para implantação. Brasília, DF, 1995.

ORGANIZAÇÃO MUNDIAL DA SAÚDE. Glossário de promoção da saúde. Genebra, 1998. 
PELICIONI, M.C.F. Qualidade de vida das mulheres trabalhadoras das creches conveniadas do bairro Bela Vista do Município de São Paulo. São Paulo, 1995. [Tese de Doutorado - Faculdade de Saúde Pública da USP].

REIGOTA, M. O que é educaçăo ambiental. Cortez, São Paulo, 1994.

SADER, E. A ecologia será política ou não será. In: GOLDENBERG, M. org. Ecologia,ciencia e política: participaçáo social, interesses em jogo e luta de idéias no movimento ecológico. Rio de Janeiro, Revan, 1992, p. 135-42.

\section{ENVIRONMENTAL EDUCATION, QUALITY OF LIFE AND SUSTENTABILITY}

SUMMARY: This paper intends to show that Environmental Education is spreading a new vision of the world among people, aiming at improving the quality of life around the planet. It concerns the valorization of life, the need of adopting a new life-style without excessive consumism, without the misuse of resources and withnet environmental degradation. It also shows the opinions of several authors about the "sustainable development" as a form of development that provides economical growth with social justice and the satisfaction of the needs of poor people.

KEY WORDS: environmental education; quality of life; sustentability. 